\title{
Electrode of Electric Double Layer Capacitor Prepared from Densified Activated Carbon Fiber
}

\author{
Young Ok CHOI, ${ }^{a}$ Kap Seung YANG, ${ }^{a, *}$ and Jong Huy KIM ${ }^{\mathrm{b}}$
}

\author{
aDepartment of Textile Engineering, Chonnam National University (300 Yongbong-dong, Buk-gu, Kwangju 500-757, \\ Korea) \\ ${ }^{\mathrm{b}}$ Korea Institute of Energy Research (P. O. Box 103 Yusong, Taejon 305-600, Korea)
}

Received June 1, 2001 ; Accepted July 6, 2001

\begin{abstract}
A coal tar based isotropic pitch was spun into fibers by using melt spinner and stabilized under air condition. The stabilized fibers was chopped and densified at 5-15 MPa and $400^{\circ} \mathrm{C}$ with no addition of binder to be bulk densities of $0.3 \sim 1.2 \mathrm{~g} / \mathrm{cc}$. The component fibers were effectively densified sustaining the original fiber shape. The densified disc was carbonized and followed by steam activation. The activated carbon disc (DACF) showed high enough electrical conductivity of $2.3 \times 10 \mathrm{~S} / \mathrm{cm}$ to be used as an electrode. The pore size distribution and BET surface area of the DACFs prepared at various activation conditions were $15-19 \AA$ and $2,023 \mathrm{~m}^{2} / \mathrm{g}$ at $82 \%$ burn-off, respectively. The BET surface area of the coal tar based ACF is normally higher than that of the ACF from petroleum based one. A unit cell of electric double layer capacitor (EDLC) was prepared with the DACFs in $7.5 \mathrm{~mol} \mathrm{dm} \mathrm{dm}^{-3} \mathrm{KOH}$ aqueous solution. The charge/discharge capacitances of the unit cell showed relatively high specific capacitances of $45 \sim 75 \mathrm{~F} / \mathrm{g}$ and $22 \sim 29$ $\mathrm{F} / \mathrm{cm}^{3}$. The AC impedance measurements of the unit cells showed a decrease in internal/interfacial resistance with an increase in burn-off and a decrease in thickness, indicating the enhanced ionic conductivity caused by both widening of pore size and an increase in surface area.
\end{abstract}

Key Words : Densified Activated Carbon Fiber, EDLC, Pore Size, Surface Area

\section{Introduction}

An activated carbon fiber (ACF) with high surface area is readily prepared from the general performance carbon fiber (GPCF) due to its isotropically connected network morphology. The ACFs exhibit high specific surface area showing adsorption-desorption with negligible hysteresis. The general applications of the ACFs are removal of SOx and NOx, purification of water, separation of gases, ion exchanges, and electrode of EDLC.

Recently, many concerns have been focused on the properties of EDLC, such as high power density, reversible kinetic mechanism, high charge-discharge efficiency $(90-96 \%)$, wide applicable temperature range. ${ }^{1,2)}$ The capacitance of the EDLC with activated carbon fiber mainly depends on its specific surface area, pore size, functional groups, electric conductivity of the electrode. ${ }^{1,3)}$

In general, the source of the pitch, such as coal tar based or petroleum based, determines the physical properties of the GPCF, the activation behavior and the adsorption behavior of the ACF. A coal tar based pitch exhibits higher aromaticity than petroleum based pitch, 0.88 and 0.97 , respectively. ${ }^{4}$ ) On the behalf of the aromaticity, the coal tar based pitch shows less reactive than the petroleum based to the oxygen in the oxidative stabilization procedure. The aromaticity difference also affects the carbonization and activation, resulting the respective layered structure in the ACF. The specific layer structure determines the concentration of active sites in the pore affecting the density of ions in the double layers for EDLC application.
Lin et al. ${ }^{5)}$ suggested that the specific capacitance of the EDLC of carbons would be $c a .20 \mu \mathrm{F} / \mathrm{cm}^{3}$ in all the pores accessible to electrolyte. The specific capacitance of the carbonaceous material is ranging from $3 \mu \mathrm{F} / \mathrm{cm}^{3}$ for the basal plane to $70 \mu \mathrm{F} / \mathrm{cm}^{3}$ for the polished graphite edge plane. ${ }^{6-8)}$ Salitra et al. ${ }^{9)}$ reported that the specific capacitance per unit area was determined by the ion sieving mechanism through the pores.

Oh $e t a l{ }^{10)}$ discussed the capacitive properties of various ACFs from different sources. NMR technique was applied to measure the specific capacitance of the ACF on adsorption/desorption of cation and anion during charge/discharge process.

Nakagawa et al. ${ }^{11-14)}$ examined the relationship between the BET surface area and the capacitance of the electrodes, which were prepared by densification of the stabilized fibers and subsequent carbonization and steam activation (DACF). In their study, the capacitance of the DACF increased with the increases in bulk density of the DACF and conductivity of electrolyte in bulk of the electrodes. Though the DACF electrodes in neutral aqueous solution of $\mathrm{KCl}$ exhibited the highest capacitance incomparable with other types of electrodes, the values were ranged $26.9-28.5 \mathrm{~F} / \mathrm{g}$.

Though the similar experimental procedures with Nakagawa's were followed, in this study, a different source pitch and different electrolyte were chosen. The oxidatively stabilized pitch fiber was densified, carbonized and finally activated to be the densified ACF (DACF) with high specific volume capacitance. The surface character- 
istics of the DACFs prepared at various conditions were measured. Charge/discharge behaviors of the unit cell in $7.5 \mathrm{~mol} \mathrm{dm} \mathrm{dm}^{-3} \mathrm{KOH}$ aqueous solutions were discussed on the basis of the bulk density of the DACF and pore characteristics.

\section{1 DACF preparation}

\section{Experimental}

The coal tar based isotropic pitch (Osaka Gas Chemicals Co., Japan, softening temperature $=312^{\circ} \mathrm{C}$ ) and petroleum based pitch (Anshan Co., China, softening temperature $=256^{\circ} \mathrm{C}$ ), was spun into fibers through a round-shaped mono-hole spinneret $(L / D=0.4 / 0.2 \mathrm{~mm})$ by pressurized nitrogen, at $325^{\circ} \mathrm{C}$ and $0.8 \mathrm{MPa}$. The pitch fibers were oxidatively stabilized stepwise at $200^{\circ} \mathrm{C}$ for 1 $\mathrm{hr}$ and successively at $300^{\circ} \mathrm{C}$ for $2 \mathrm{hrs}$ by air. The petroleum based pitch was just used for the comparison with coal tar based pitch in oxidative stabilization behavior.

The stabilized fibers were chopped and clensified into discs in molds with sizes of 5 or $10 \mathrm{~cm}^{2}$ after uniformly dispersing the fibers in the mold (Fig. 1) at 5-15 MPa and at $400^{\circ} \mathrm{C}$ for $10 \mathrm{~min}$. The discs were carbonized at $1,000^{\circ} \mathrm{C}$ for $1 \mathrm{hr}$ under argon atmosphere and followed by steam $\left(\mathrm{H}_{2} \mathrm{O} / \mathrm{N}_{2}=0.4\right.$ by volume $)$ activation at $800 \sim$ $1000^{\circ} \mathrm{C}$ for $30 \sim 120 \mathrm{~min}$. The heating rates were fixed at $5{ }^{\circ} \mathrm{C} / \mathrm{min}$ for the stabilization, densification, carbonization, and $10^{\circ} \mathrm{C} / \mathrm{min}$ for the activation. Figure 2 shows the overall procedures of the experiments.

\section{2 Characterizations}

Softening temperature of the precursor was measured by using Mettler FP 90 apparatus (Mettler-Toledo AG, Switzerland). C, H, N content in a sample was determined from elemental analysis (Elemental Analyzer, CE Instruments, Italy) and $\mathrm{O}$ content was calculated through subtracting the $\mathrm{C}, \mathrm{H}, \mathrm{N} \%$ from 100 . Thermogravimetrical analysis (TGA 2950, TA Instruments, USA) was performed under air or nitrogen atmosphere to find opti-

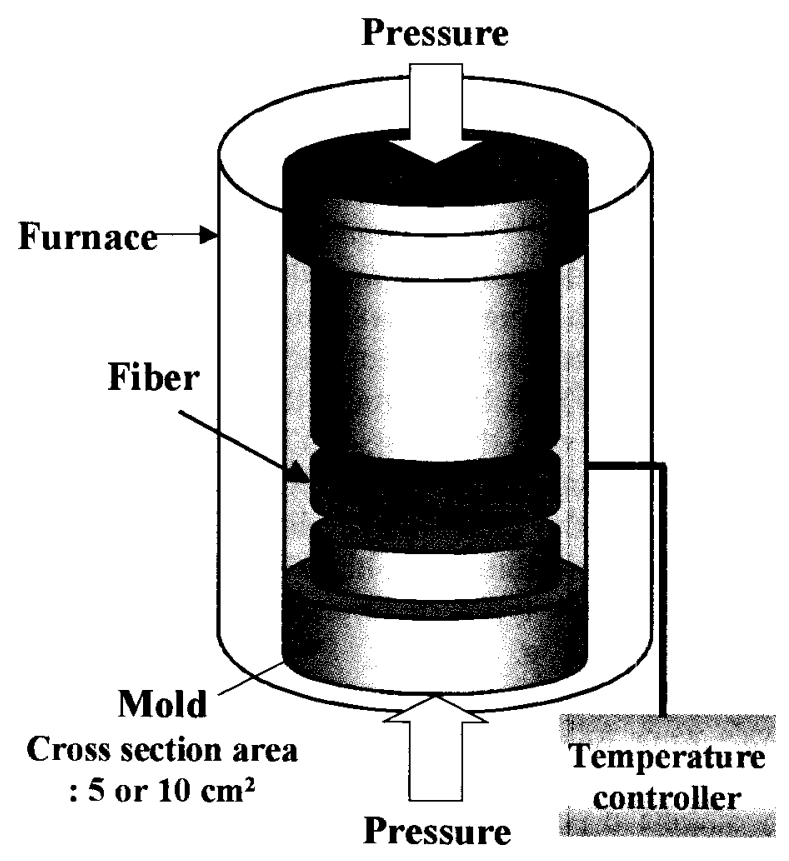

Fig. 1 The densification apparatus. mized stabilization condition or to measure the thermal stability of the samples. SEM (Hitachi, S-4700, Japan) was used to observe the surface and cross sectional features of the densified discs. X-ray diffraction (Dmax 1200, Rigaku, Japan) was used to characterize the layered structure. BET surface area and pore size were measured by a Micromeritics ASAP 2010 (USA) through $\mathrm{N}_{2}$ adsorption isotherm at $77.4 \mathrm{~K}$ in the range of relative pressure $\left(P / P_{0}\right)$ of $10^{-6}-1$. The micropore analysis was performed by using MP method and $t$-plot. The mesopore volume distribution was calculated on the basis of the BJH theory. The BJH method is based on Kelvin equation, which relates the relative pressure of nitrogen in equilibrium with the size of the pores of a solid taking place of capillary condensation. The pore size radii available to the $\mathrm{BJH}$ calculations are ranged from 17 to $3000 \AA$.

The electrical conductivities of the DACF were measured by 4-probe method.

2. 3 Measurement of unit cell capacitance and $\mathrm{AC}$ impedance

The EDLC unit cell composed of two DACFs and $\mathrm{Ni}$ current collector, sufficiently wetted in $7.5 \mathrm{~mol} \mathrm{dm} \mathrm{dm}^{-3}$ $\mathrm{KOH}$ aqueous electrolyte, was monitored by using the Capacitor Cycle Test System HPS-2043 (Arbin Co., USA). The unit cell was first charged upto $0.9 \mathrm{~V}$ at the current density of $10 \mathrm{~mA} / \mathrm{cm}^{2}$ and sustained for $10 \mathrm{~min}$ and then discharged at $1 \sim 50 \mathrm{~mA} / \mathrm{cm}^{2}$. The capacitance was calculated on the basis of changes of voltage as a function of discharging time (Equation (1)).

$$
C=(I \times \Delta t) / \Delta V
$$

where $C$ is capacitance in farad ; $I$, discharge current in ampere $; \Delta t$, lapse of discharge time in sec; $\Delta V$, variation of voltage as a function of discharge time. The ca-

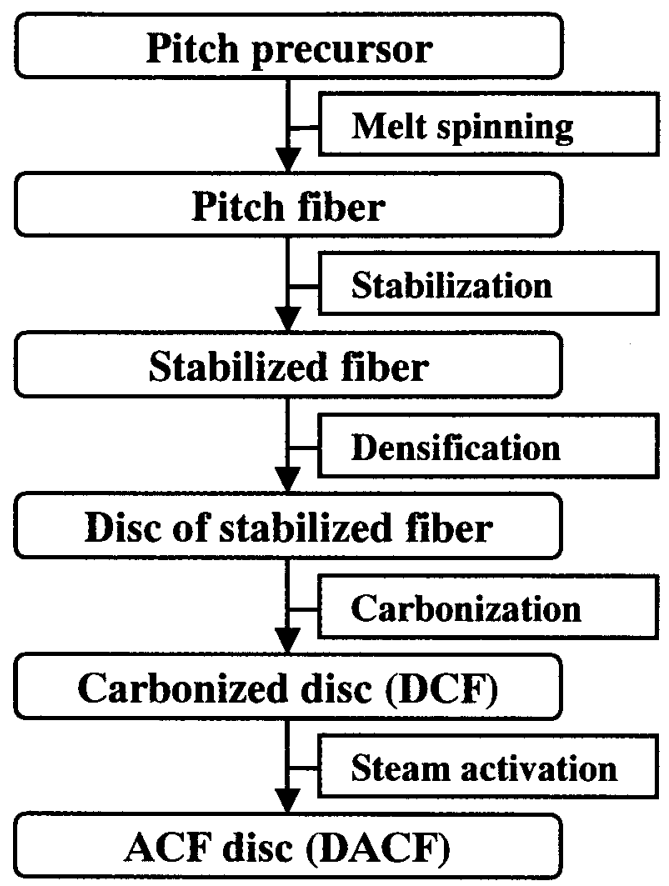

Fig. 2 The overall procedures of experiment. 
pacitance of the unit cell calculated on the basis of equation (1) was converted into the specific capacitance per unit mass or volume.

Impedance of a unit cell was measured by using Cyclic Voltametry (IM6, Zahner, Germany) to measure resistances of the system of DACF electrode involved in the electrolyte solution.

\section{Results and Discussion}

Figure 3 shows the TGA thermoprofiles of the petroleum based (Anshan) and coal tar based (Osaka) pitch under air atmosphere. A weight gain was observed by $0.5-1.2 \%$ in the range of $200^{\circ} \mathrm{C}-450^{\circ} \mathrm{C}$, due to oxygen uptake. The maximum weight gain of Osaka pitch was about $0.6 \%$, while that of Anshan pitch was above $1 \%$, representing that petroleum based pitch is more reactive to oxygen than coal tar based pitch is.

Elemental analysis data were summarized in Table 1. Most of samples contain the carbon content above $90 \%$ except stabilized fiber due to the oxygen uptake. Suffi-

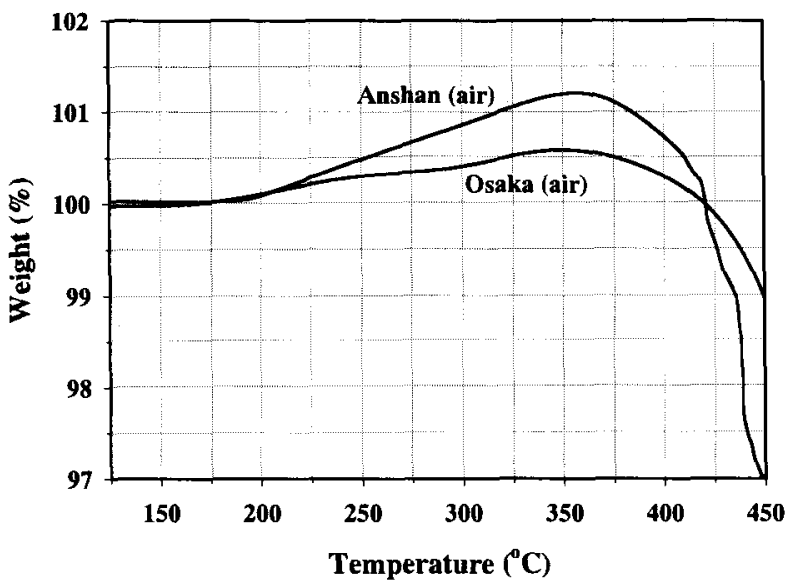

Fig. 3 TGA thermoprofiles of coal tar based and petroleum based pitches under air atmosphere ; heating rate, $5{ }^{\circ} \mathrm{C} / \mathrm{min}$.

Table 1 Elemental contents in the samples from coal tar based pitch.

\begin{tabular}{|c|c|c|c|c|}
\hline & $\mathrm{C}(\%)$ & $\mathrm{H}(\%)$ & $\mathrm{N}(\%)$ & $\mathrm{O}(\%)$ \\
\hline Pitch Precursor & 92.83 & 4.09 & 1.10 & 1.98 \\
\hline Pitch fiber & 92.76 & 4.10 & 1.10 & 2.04 \\
\hline Stabilized fiber & 80.54 & 2.63 & 1.02 & 15.81 \\
\hline $\begin{array}{c}\text { Carbonized fiber } \\
\text { at } 1,000^{\circ} \mathrm{C}\end{array}$ & 91.30 & 0.66 & 0.85 & 7.19 \\
\hline
\end{tabular}

cient stabilization was recognized with the high oxygen content of $15.8 \%$ which was required for pressured densification of the stabilized fiber sustaining the original shape of the fibers. The oxygen uptake of the referred study ${ }^{14)}$ was $24 \%$ and it was considered that the sources of the pitch was petroleum based one.

The bulk density was generally increased with increasing the loaded pressure (Fig. 4). Stable disc was formed without additions of binder and sustaining the round shape of the individual fibers, with a bulk density of 0.3 $1.2 \mathrm{~g} / \mathrm{cc}$. This bulk density could be controlled by the weight of loaded sample and pressure.

SEM microphotographs of densified carbon fiber disc (DCF) (Fig. 5) showed the effective densification sustaining the initial shape of the fiber. The homogeneous vacant space among the component fibers was understood to be large enough for flowing the steam/nitrogen mixture for activation procedure.

The burn-off was increased with increasing activation temperature and time (Fig. 6). When DCF was activated at $900^{\circ} \mathrm{C}$ in $120 \mathrm{~min}$., the disc was burnt out.

Figure 7 shows the $\mathrm{N}_{2}$ adsorption/desorption isotherms of DACFs at $77.4 \mathrm{~K}$. The nitrogen uptake was significant only in the low-pressure region. At higher relative pressure, no further adsorption was observed and the adsorption curve reached equilibrium. According to the IUPAC classification, these curves resemble the type I isotherm which represents microporous carbon having a relatively small external surface area. ${ }^{15,16)}$ The volume of adsorbed nitrogen was increased with the burn-off increase, representing the surface area increase

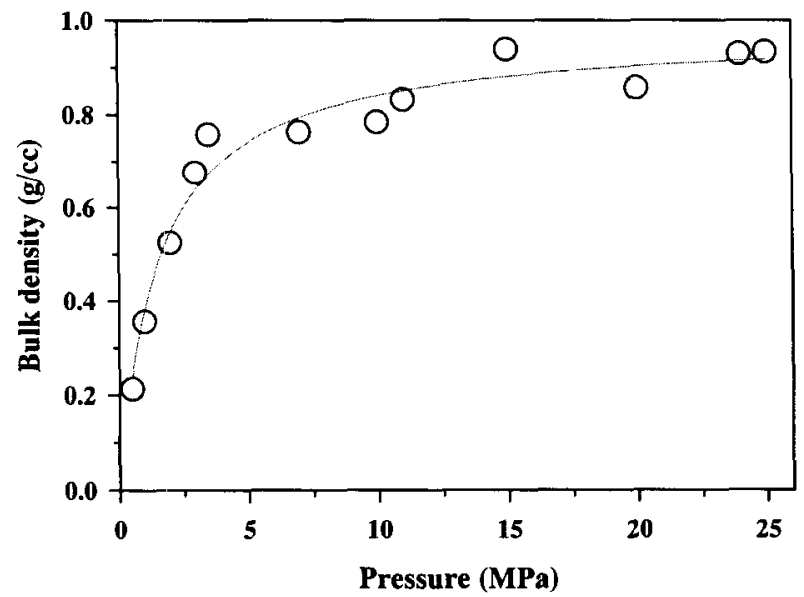

Fig. 4 The effect of pressure on the bulk density.
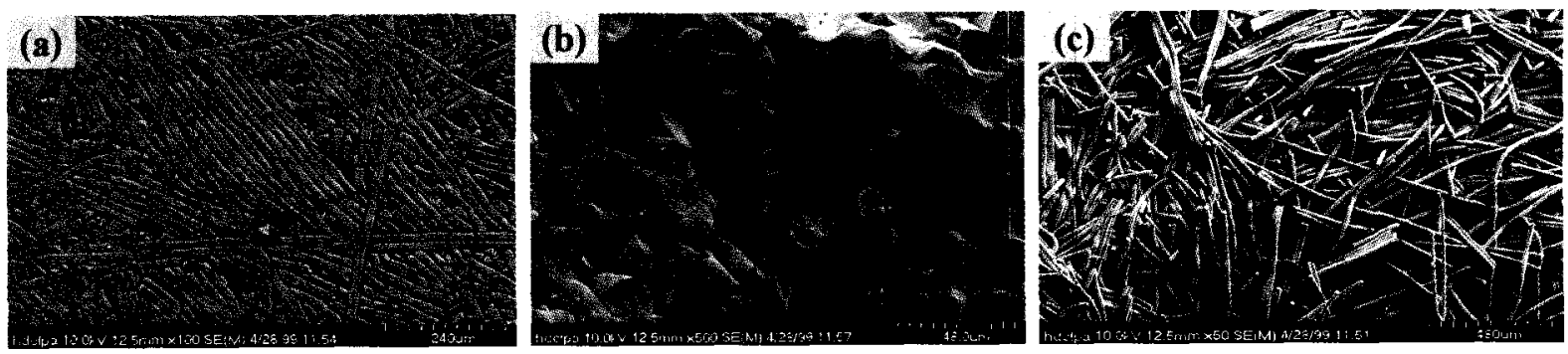

Fig. 5 SEM microphotographs of DCF pressed at $20 \mathrm{MPa}, 400^{\circ} \mathrm{C}$ for 10 minutes ; (a) surface, (b) cross section, (c) inner side. 


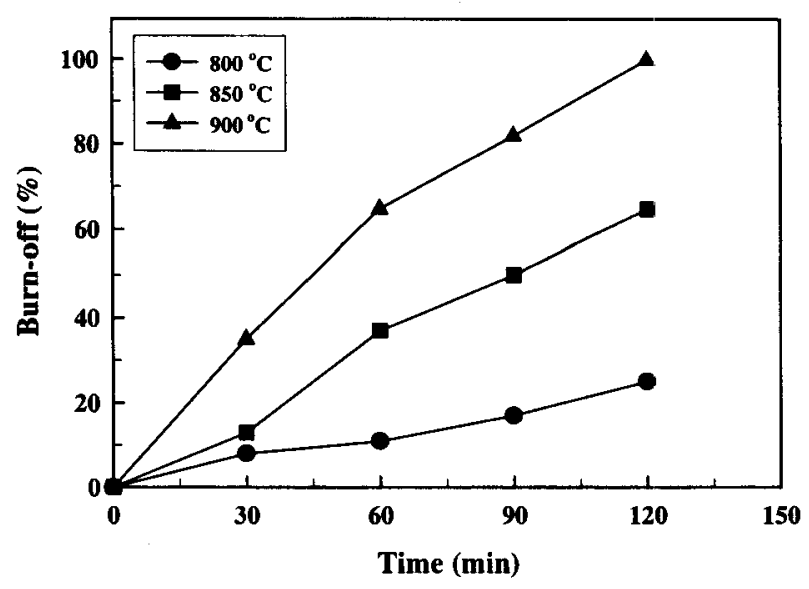

Fig. 6 The burn-off $\%$ as the function of activation time.

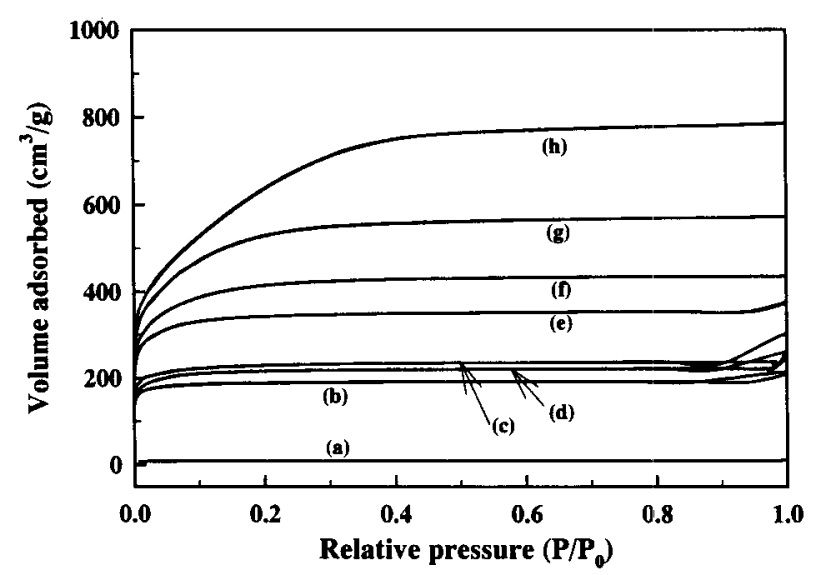

Fig. 7 The N2 adsorption/desorption isotherms of DACFs with various burn-offs at $77.4 \mathrm{~K}$; (a) $0 \%$, (b) $13 \%$, (c) $20 \%$, (d) $30 \%$, (e) $40 \%$, (f) $50 \%$, (g) $66 \%$, (h) $82 \%$.

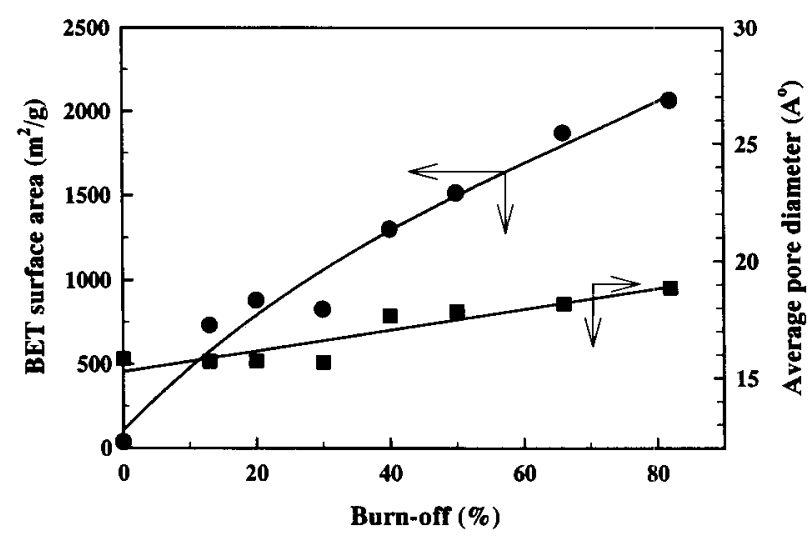

Fig. 8 BET surface area and average pore diameter of DACF as a function of burn-off.

of DACFs. DACFs with low burn-offs (b, $c$ and d) show the hysteresis loops at the higher pressure which result from Mcbain's bottle-neck pores. In the pores with this shape, emptying of the wide portion will be delayed during desorption through the narrowed necks. Therefore, the desorption curve exhibits a smaller slope at elevated relative pressure and a larger slope where the wide part of the pore empties. ${ }^{16-18)}$
Table 2 Variations in the surface area, pore volume, pore size distribution and average pore diameter with the levels of burn-off for DACF.

\begin{tabular}{cccccc}
\hline & BET & Pore & \multicolumn{2}{c}{ Pore volume fraction } & Average \\
$(\%)$ & $\begin{array}{c}\text { surface } \\
\text { area } \\
\left(\mathrm{m}^{2} / \mathrm{g}\right)\end{array}$ & $\begin{array}{c}\text { volume } \\
\left(\mathrm{cm}^{3} / \mathrm{g}\right)\end{array}$ & $\begin{array}{c}\text { Micropore Mesopore } \\
(\%)\end{array}$ & $\begin{array}{c}\text { More } \\
\text { diameter }\end{array}$ \\
\hline 0 & 34 & 0.016 & 100 & 0 & 15.82 \\
13 & 730 & 0.287 & 99.54 & 0.46 & 15.72 \\
20 & 877 & 0.366 & 99.09 & 0.91 & 15.73 \\
30 & 832 & 0.326 & 99.16 & 0.84 & 15.67 \\
40 & 1,319 & 0.582 & 98.79 & 1.21 & 17.66 \\
50 & 1,512 & 0.600 & 98.52 & 1.48 & 17.86 \\
66 & 1,950 & 0.886 & 98.29 & 1.71 & 18.18 \\
82 & 2,023 & 0.955 & 96.08 & 3.92 & 18.87 \\
\hline
\end{tabular}

Figure 8 shows the BET surface area and average pore diameter as a function of burn-off and the results were summarized in Table 2. Disc with no burn-off, DCF, exhibits very small BET surface area from the micropores. One can observe that the surface area and pore volume generally increase with an increase of the burnoff level except $30 \%$ burn-off case. An increase in the volume proportion of mesopore over micropore was observed with increasing the burn-off, which corresponds with the increase in average pore diameter. Not only an increase of surface area but also enlarging the pore size were occurred with proceeding burn-off. The ACF prepared from coal tar based pitch exhibits higher surface area than the ACF from petroleum based one.

Figures 9 and 10 show capacitance per unit weight and unit volume, respectively, as a function of discharging current density. The specific weight capacitances were in the range of $45-75 \mathrm{~F} / \mathrm{g}$. The values are relatively higher than those from HDACF electrodes prepared from petroleum pitch based in the $\mathrm{KCl}$ solution as reported of 26.9$28.5 \mathrm{~F} / \mathrm{g}{ }^{14)}$ Unit cell with DACF at $48 \%$ burn-off showed the highest specific capacitance among the four cases. The specific volume capacitances are shown in Fig. 10, ranged $22-29 \mathrm{~F} / \mathrm{cm}^{3}$. The cells show the specific volume capacitance in the order of $20 \%, 48 \%, 30 \%$ and $24 \%$ burn-off. From these results, one can conclude that the specific mass capacitance mainly depends on the surface area but the specific volume capacitance depends on the surface area density per unit volume.

Electric conductivities of the samples were summarized in Table 3 . The electric conductivity was reduced to be $1 / 7$ by activation and further reduced by formation disc due to the contact resistance among fiber components in the DACF. The electrical conductance of $30 \%$ burn-off DACF was $2.3 \times 10 \mathrm{~S} / \mathrm{cm}$ which is high enough for the application of electrode.

The unit cell of the EDLC was also prepared from the commercial ACF cloth (bulk density of $0.2-0.3 \mathrm{~g} / \mathrm{cc}$, BET surface area of $1,500 \mathrm{~m}^{2} / \mathrm{g}$ ) and tested in the same conditions with the DACF EDLC. The capacitances were 60 $\mathrm{F} / \mathrm{g}$ and $19.6 \mathrm{~F} / \mathrm{cm}^{3}$. The specific capacitances from the DACF (bulk density $0.4 \mathrm{~g} / \mathrm{cc}$, BET surface area of $c a$. 


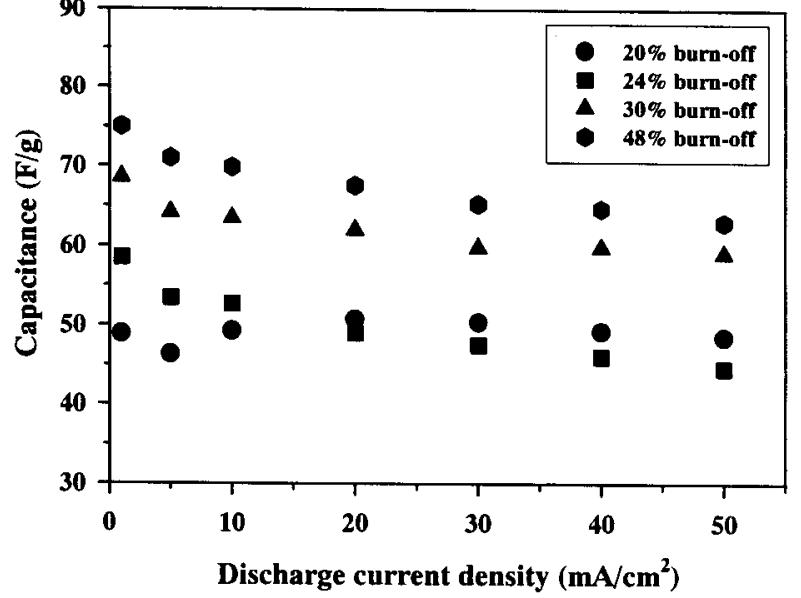

Fig. 9 Specific weight capacitance $(\mathrm{F} / \mathrm{g})$ dependencies on the discharge current density.

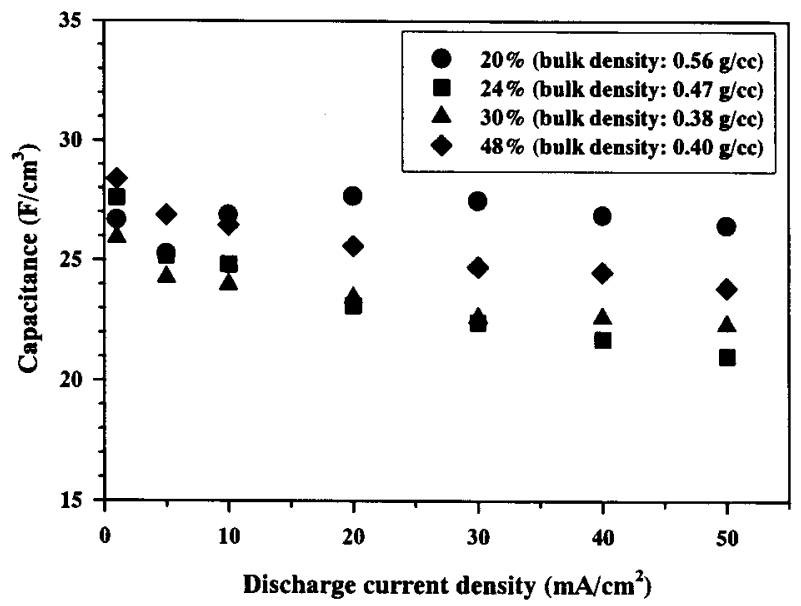

Fig. 10 Specific volume capacitance $\left(\mathrm{F} / \mathrm{cm}^{3}\right)$ dependencies on the discharge current density.

Table 3 The electric conductivity of DACF prepared from coal tar based pitch.

\begin{tabular}{cc}
\hline Sample & Conductivity $(\mathrm{S} / \mathrm{cm})$ \\
\hline CF (fiber form) & $2.2 * 10^{2}$ \\
ACF (fiber form) & $3.2 * 10$ \\
DACF (disc form) & $2.3 * 10$ \\
\hline
\end{tabular}

$1,500 \mathrm{~m}^{2} / \mathrm{g}$ ) increased by $25 \%$ in unit volume and $12 \%$ in unit mass. This suggests that densification technique is an effective method to achieve an elevated specific volume capacitance.

The specific weight capacitance was increased upto $1,000 \mathrm{~m}^{2} / \mathrm{g}$ rather sharply and slowly from above the surface area, representing inefficient pore structure for formation of double layer on the surface above the 1,000 $\mathrm{m}^{2} / \mathrm{g}$ (Fig. 11). The capacitance per BET surface area is calculated on the basis of data in Table 2 and plotted in Figure 12. The capacitance was increased with an increase of surface area up to $1,000 \mathrm{~m}^{2} / \mathrm{g}$, but slowly decreased with further increase in specific surface area. The capacitance per BET surface area was calculated to be range of $5-7 \mu \mathrm{F} / \mathrm{cm}^{2}$ which is about $1 / 10$ the average

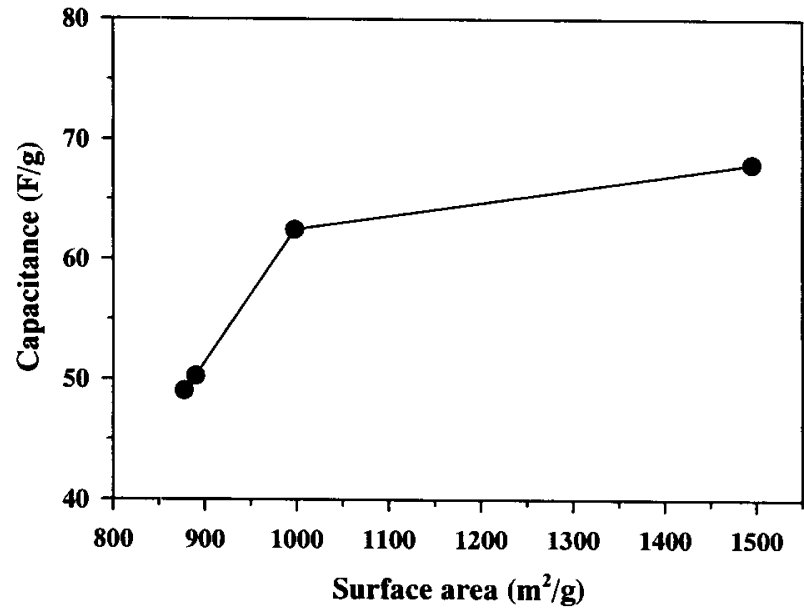

Fig. 11 Specific weight capacitance dependencies on the surface area of DACFs.

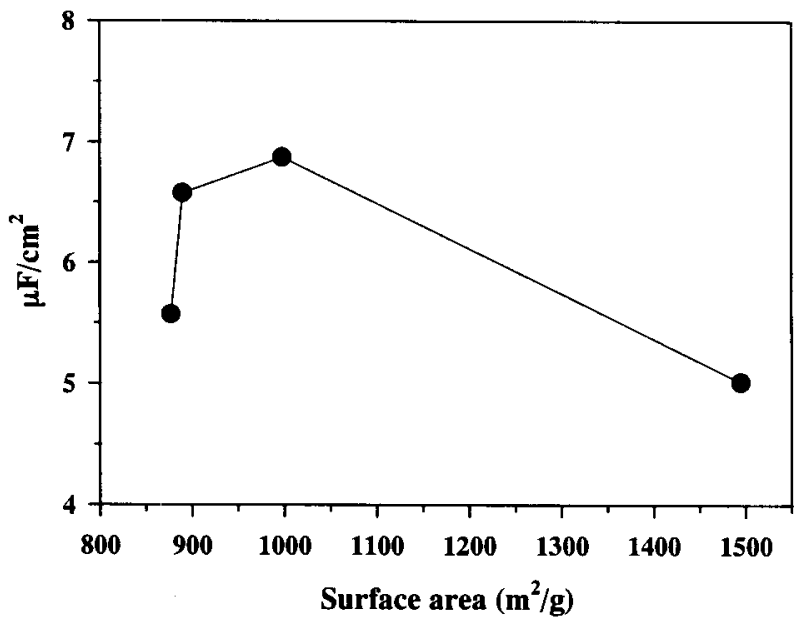

Fig. 12 Specific capacitance per BET surface area of DACFs.

of the capacitance of graphite edge plane. In the case of pyrolytic carbon, the theoretical capacitance per BET surface area is in range of $50-70 \mu \mathrm{F} / \mathrm{cm}^{2}$ on edge plane and $3 \mu \mathrm{F} / \mathrm{cm}^{2}$ on basal plane. ${ }^{14)}$ The results suggest that optimum size of the pore would maximize the double layer formation of the ions on the surface of the pore, overcoming the sieving function of the pores to the electrolytes solvated with $\mathrm{H}_{2} \mathrm{O}$, as suggested by Salitra. ${ }^{9}$ )

$\mathrm{AC}$ impedance was dependent on the thickness and burn-off of the DACF which would be correlated with surface area and pore sizes of the electrode (Fig. 13), affecting the mobility and diffusion of the electrolytes. In charge transfer process (semicircle region at high frequency), the electrolyte internal resistance showed no difference regardless of burn-off and thickness of electrode. But the interfacial resistance in the electrode/electrolyte interface was decreased with an increase in burnoff and with a decrease in the thickness. This is thought as results of the enhanced ion conductivity by widening of pore and the increase of surface area. In mass transfer process, linear inclination of impedance at medium frequency represents that the cations diffused into specific site of carbon electrode. As the result, the higher the burn-off $\%$ and the thinner the thickness of electrode, the lower impedance of unit cell is observed. 


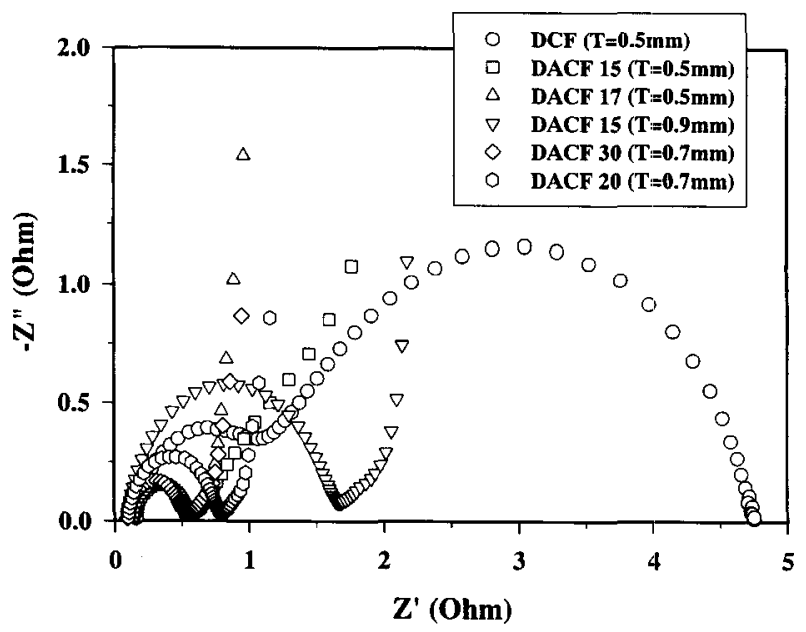

Fig. 13 Nyquist plots of DACF electrodes at several burnoffs and thickness ; DACF 15-15\% burn off; DACF $17-$ $17 \%$ burn off ; DACF $20-20 \%$ burn off ; DACF $30-30 \%$ burn off ; $\mathrm{T}$-thickness.

\section{Conclusions}

The coal tar based optically isotropic pitch precursor was spun into fibers, oxidatively stabilized, densified and carbonized to be DCF. All component fibers were effectively densified with no binder and any deformation of individual fibers at bulk density of $0.3 \sim 1.2 \mathrm{~g} / \mathrm{cc}$. Fibers were isotropic and showed the low ordered structure, indicating suitable for preparation of ACF. DACFs were prepared from the DCFs through steam activation.

The DACFs were applied for the electrodes of cointype EDLC. From the charge-discharge test, the unit cells showed the high specific capacitances of $45-75 \mathrm{~F} / \mathrm{g}$ and $22-29 \mathrm{~F} / \mathrm{cm}^{3}$, which increased by $12 \%$ and $25 \%$ respectively from the those of commercialized ACF cloth. The values are higher than those of electrodes prepared from the petroleum based pitch in $\mathrm{KCl}$ solution reported. Though the preparation of DACF is considered to be the effective technique to increase specific volume capacitance, further developments of the technique for the preparation of preferred pore size are required. The layered structure in accessing the active site to electrolyte ions is also necessary. Unit cell of DACFs as electrode showed the decreased interfacial resistance between the electrode and electrolyte with increasing the burn-off and decreasing the thickness, representing the enhancement in ion mobility by widening of pores, an increase in contact area between electrolytes and electrode through enlarging the surface area.

\section{Acknowledgements}

This research was performed with cooperation of Korean Institute of Energy Research through the fund of the project "Critical Technology 21".

\section{References}

1) K. Kinoshita and X. Chu, The Electrochemical Society Proceedings, 29, 171 (1995).

2) A. Yoshida, I. Tanahashi, and A. Nishino, Carbon, 28, 611 (1990).

3) A. Yoshida, Functional Materials, 33-64 (1989).

4) H. Marsh, E. A. Heintz, and F. Rodriquez-Reinoso, in "Introduction to Carbon Technology", University of Alicante, Secretarado de publications, 1997, p. 435

5) C. Lin, J. A. Riter, and B. N. Popov, J. Electrochem. Soc., 146, 3639 (1999).

6) K. Kinoshita, Carbon, Electrochemical and Physicochemical Properties, Chap. 6, John Wiely \& Sons, Inc., New York (1998).

7) J. P. Randin and E. B. Yeager, J. Electroanal. Chem., 36, 257 (1972).

8) A. Soffer and M. Folman, J. Electrochem. Soc., 38, 25 (1972).

9) G. Salitra and A. Soffer, J. Electrochem. Soc., 147, 2486 (2000).

10) S. J. Oh, Y. Korai, and I. Mochida, Ext. Abstr., The 26nd Annual Meeting of Carbon Society of Japan, 1999, p. 132.

11) K. Miura and H. Nakagawa, Chemical Engineering (Japan), 1997, p. 1.

12) K. Miura and H. Nakagawa, Ext. Abstr., The 26nd Annual Meeting of Carbon Society of Japan, 1999, p. 144.

13) K. Miura, H. Nakagawa, and H. Okamoto, Carbon, 38, $119(2000)$.

14) H. Nakagawa, A. Shudo, and K. Miura, J. Electrochem. Soc., 147, 38 (2000).

15) S. Lowell and J. E. Shields, in "Powder surface area and porosity", Vol. 3, London, Chapman \& Hall, 1981. p. 55.

16) Nasrin R. Khalili, Marta Campbell, Giselle Sandi and Janusz Colas, Carbon, 38, 1905 (2000).

17) Petr Schneider, Applied Catalysis A : General, 129, 157 (1995).

18) Kenneth S. W. Sing, Advances in Colloid and Interface Science, 76-77, 3 (1998). 